\title{
Sustaining $99.99 \%$ Reliability for US Electric Grid by using Renewable Energy Systems Complexity as a Benefit
}

\author{
Henri Francois \\ University of Notre Dame \\ Anne Stratman \\ University of Notre Dame \\ Robert Stiller \\ University of Notre Dame \\ Brady McLaughlin \\ University of Notre Dame \\ Deseré e Frink-Larca \\ University of Notre Dame \\ Janaya Brown \\ University of Notre Dame
}

Abigail Mechtenberg ( $\sim$ amechten@nd.edu )

University of Notre Dame https://orcid.org/0000-0001-7893-6181

\section{Article}

Keywords: renewable energy, high-income countries, low-to-middle-income countries

Posted Date: October 11th, 2021

DOl: https://doi.org/10.21203/rs.3.rs-961374/v1

License: (9) This work is licensed under a Creative Commons Attribution 4.0 International License.

Read Full License 


\title{
Sustaining 99.99\% Reliability for US Electric Grid by using Renewable Energy Systems Complexity as a Benefit
}

\author{
Abigail Mechtenberg* \\ ND Energy and Physics Department \\ University of Notre Dame. \\ Henri E. Francois \\ ND Energy and Computer Science \\ University of Notre Dame.
}

Anne Stratman, Robert Stiller, and Brady McLaughlin ND Energy and Physics Department University of Notre Dame

Desereé Frink-Larcart

ND Energy, Physics Department and Computer Science

University of Notre Dame

Janaya Brown

ND Energy and Aerospace and Mechanical Engineering University of Notre Dame

(Dated: October 11, 2021)

\begin{abstract}
Renewable energy system designers in status-quo and high-income countries (HICs) work to improve the environmental and societal impacts of energy systems by using increasingly complex technologies to predict the future. However, low-to-middle-income countries (LMICs) focus on innovative solutions by turning complexity into an asset. This paper presents the results from four optimization objectives, presented as scenarios with data from EIA utility regions, and with powerloads scaled using population data, solar radiance, wind speed, and wastewater treatment plant (WWTP) capabilities for biogas turbines. This allowed for the complexity of renewable energy systems to be used as a benefit instead of a deficit. For many US cities, an emerging LMIC-based optimization pathway can make possible energy system designs that increase reliability by including backup biogas generators. Here we show that the HIC-based approach is optimal for some cities; for others the status-quo pathway; for many, surprisingly, the LMIC approach is optimal.
\end{abstract}

\section{INTRODUCTION}

Although the United States is implementing solar, wind and battery systems into the grid with various optimization algorithms [1-5] and socio-economic as well as socio-technical objective functions and/or constraints [6$15]$, the pace of change is considered too slow and costly for the rapid integration needed to avoid the emerging global climate crisis and devastation from what writer Elizabeth Kolbert calls the "sixth extinction" [16]. Using frogs, who were the earliest representation of modern amphibians, as a timeline to predate mammals and birds, Kolbert argues that the high rate of extinction of frogs is a harbinger of an imminent extinction event, based on previous observed rates. In the face of low-cost and reliable electricity, how can large-scale change occur [16]? The authors believe that large scale change is possible by looking at places with limited economic resources as well

*amechten@nd.edu as inaccessible and/or unreliable electricity [17-23] even without tariffs [24, 25] (although tariffs would be preferable to costs during energy crises, especially considering VSL/E hidden energy costs at health care facilities [26]).

The resounding interest in renewable energy has been heightened by the consistent realization that global climate modeling underestimates instability and the potential for a sixth extinction. In fact, many climate results continue to indicate results worse than originally predicted. A shift to a clean, smart grid will necessitate the integration of clean energy sources [14, 27]. Furthermore, it requires sizable energy storage devices (ESDs) to limit the increase in global average temperature below $2^{\circ} \mathrm{C}[28]$. However, these systems are not enough. Innovation is needed as an addition to diversification of systems. Diversified and innovative sustainable back-up energy systems are needed to continue to depend on $100 \%$ grid reliability in the 21st century and beyond [29].

Currently, California faces significant hurdles in incorporating solar energy into the California Independent System Operator (CAISO). In 2013, CAISO published 


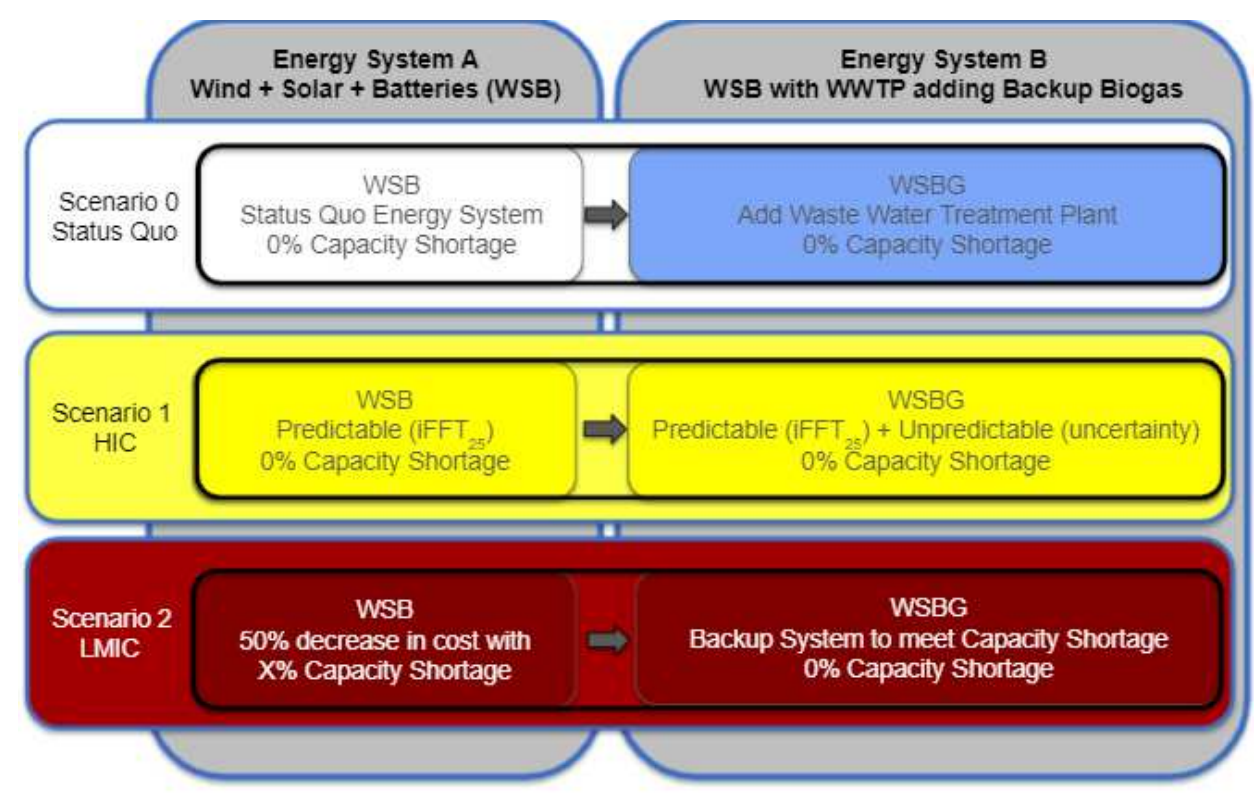

FIG. 1. There are two sets of three scenarios. There are two status quo designs for Scenario 0 (0A-WSB and 0B-WSB+BG), one HIC-based scenario using technology prediction modeling (1A- iFFT + 1B- Backup for 100\% reliability = Scenario 1), and one LMIC-based scenario (2A- 20\% Capacity shortage + 2B Backup for $100 \%$ reliability = Scenario 2).

the "duck chart" [30], which shows a serious decline in mid-day net load as solar photovoltaics (PV) are added to the grid. The duck chart suggests that the CAISO will be inadequate accommodation for the ramp rate and range needed to fully utilize solar energy. The major consequences of this effect are overgeneration and curtailing of renewable energy, which increases the cost of using clean energy and decreases its environmental benefits. A study by the National Renewable Energy Laboratory (NREL) analyzed this predicament and showed the best solution for this dilemma is to allow, or even require, distributed PV and storage as well as to provide grid services to enhance system flexibility [31]. It is no stretch to conclude that the US power grid is insufficient to incorporate a meaningful amount of clean energy without sizable ESDs [32-34] back-up diversified sustainable generators (also called gas or thermal power plants, depending on their size and energy source).

The United States has one of the highest per capita carbon emissions in the world [35]. Despite global progress, political barriers still hamper attempts to transition the energy system away from fossil fuels towards renewable energy technologies, both in the US and globally [36]. Although the U.S has faltered in leadership, exemplified through its exit of the Paris Climate Accords in 2017, it has been a leader in supporting renewable energy technology research. This research aims to explore various potential pathways for faster adoption and promotion of renewable energy systems. This exploration will allow for discussion of potential tradeoffs between high-technology designs within high-income countries (HIC) using prediction-based modeling, and economically-constrained designs based on LMIC inno- vations.

To evaluate the two pathways, the authors developed a four-step analysis methodology using 2 sets of three scenarios. Figure 1 shows the four steps as four different colors: white, blue, yellow and maroon. In all methodologies, there is either a first energy system (A), second energy system (B), or combined optimal energy solution calculated from first energy system with constraints (1A and $2 \mathrm{~A}$ ) resulting as inputs into second energy system (1B and 2B) to calculate optimal design and control system for Scenario 1 and Scenario 2. The first energy system optimally sizes solar pv, wind turbines, batteries and converters to meet the power load. The status-quo system is then hybridized with an additional energy system that always has biogas from WWTPs using peerreviewed as well as commercial viable technologies and prices $[10,32,37-47]$. There are three key scenarios: a status-quo pathway, a technology pathway with prediction (design with $i F F T_{25}$ predictions with backup biogas generators to account for uncertainties resulting in $100 \%$ reliability), and an innovation pathway (design for a $50 \%$ decrease in LCOE by accepting some percentage of capacity shortage and add backup biogas to decrease capacity shortage to zero and thus resulting in $100 \%$ reliability). Using HOMER Pro, MatLab, and Google CoLab (in python), results are presented with some cities' LCOE smallest found using the LMIC-based optimized energy systems pathway (Scenario 2) while other cities demonstrated lower levelized cost of electricity (LCOE) from the high technology HIC-based optimized energy systems pathway (Scenario 1), depending on the US city. There were cities also with Scenario $0 \mathrm{~A}$ and $0 \mathrm{~B}$ with the lowest LCOE calculated. As optimization experts know, 
the optimization algorithm pathway(s) can greatly determine the optimal design calculated [19]. The authors' methodology highlights the importance in using the complexity of renewable energy as a benefit in terms of the three pillars of sustainability (not just the two common pillars). Considering the economic, environmental, and even social assumptions and constraints (i.e. conditions) in energy optimal design and operation is vital [48], including retrofitting existing technology

\section{METHODOLOGY}

Conquering the fear of unreliable electricity should be science driven by optimal solutions from robust engineering design and controls under uncertainty. Likewise, confidence in renewable energy must be based on statistically strong science, including design and control energy system solutions calculated from optimization algorithms using uncertainty. The complexity of energy systems based on human behavior and weather accounts for this uncertainty and various human geopolitical systems choose different pathways which we summarize into four scenarios. These four scenarios design and control optimal energy systems use the complexity and uncertainty of renewable energy as a benefit, rather than a deficit.

As indicated in Figure 1, the methodology consists of four relevant scenarios: Scenario 0A, Scenario 0B, Scenario 1 (HIC optimization approach), and Scenario 2 (LMIC optimization approach). However, Scenario 1 has two sub-scenarios and Scenario 2 has three sub-scenarios. These seven sub-scenarios were analyzed using Homer Pro to calculate the optimal energy system via a greedy optimization approach. Based on the knowledge of the benefits of adding the HIC and LMIC methods, our scenarios considered new optimal regions not covered by the industry standard for optimally designing mini grids.

\section{Scenario 0A: WSB Status Quo Model}

Scenario 0A model consists of a minigrid with EIA measured region power load scaled by population for specific city power load, wind turbine (with wind speed @50m and elevation), converter, solar panels (with solar radiance), and batteries.

Homer Pro optimally sizes the solar panels, ESDs, converters, and wind turbines to meet a city load for $100 \%$ reliability. The assumptions in each model are explained in more detail in supplemental materials. The energy system options that meet the city power load and constraints are ranked based on net present value cost which is reported in the result section in terms of LCOE.

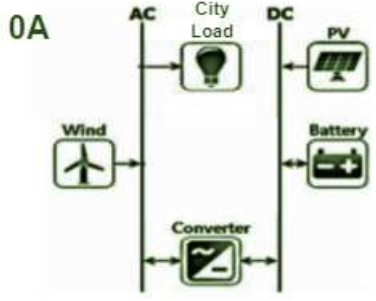

FIG. 2. Homer Pro mini grid model used for Scenario 0A optimization algorithm with solar, wind, and batteries only with no power load prediction and no novel optimization pathway considerations. There are 100 Homer Pro models using Homer Energy's API algorithm which is one for each of the 100 US cities.

\section{Scenario 0B: WSB with WWTP Status Quo Model}

Scenario 0B model consists of a minigrid with EIA measured region power load scaled by population for specific city power load, wind turbine (with wind speed @50m and elevation), converter, solar panels (with solar radiance), batteries and WWTP biogas generator added.

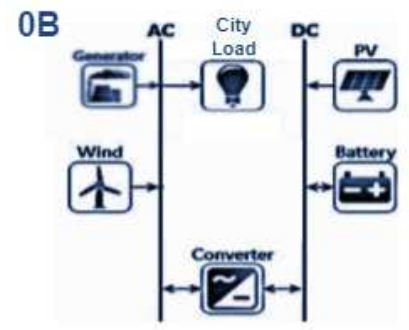

FIG. 3. Homer Pro mini grid model used for Scenario 0B optimization algorithm with solar, wind, batteries, and WWTP biogas power generation with no power load, solar radiance, and/or wind speed prediction and no novel optimization pathway considerations. There are 100 Homer Pro models using Homer Energy's API algorithm which is one for each of the 100 US cities.

Homer Pro optimally sizes the solar panels, ESDs, converters, wind turbines, and size of biogas generator to meet a city load for $100 \%$ reliability. The assumptions in each model are explained in more detail in supplemental materials. As with scenario $0 \mathrm{~A}$, the energy system options that meet the city power load and constraints are ranked based on net present value cost which is reported in the result section in terms of LCOE.

\section{Scenario 1: HIC-based Model}

Scenario 1A model consists of a minigrid with a predicted EIA region power load scaled by population for specific city power load, wind turbine (with predicted wind speed @50m and elevation), converter, solar panels (with predicted solar radiance), and batteries, but 

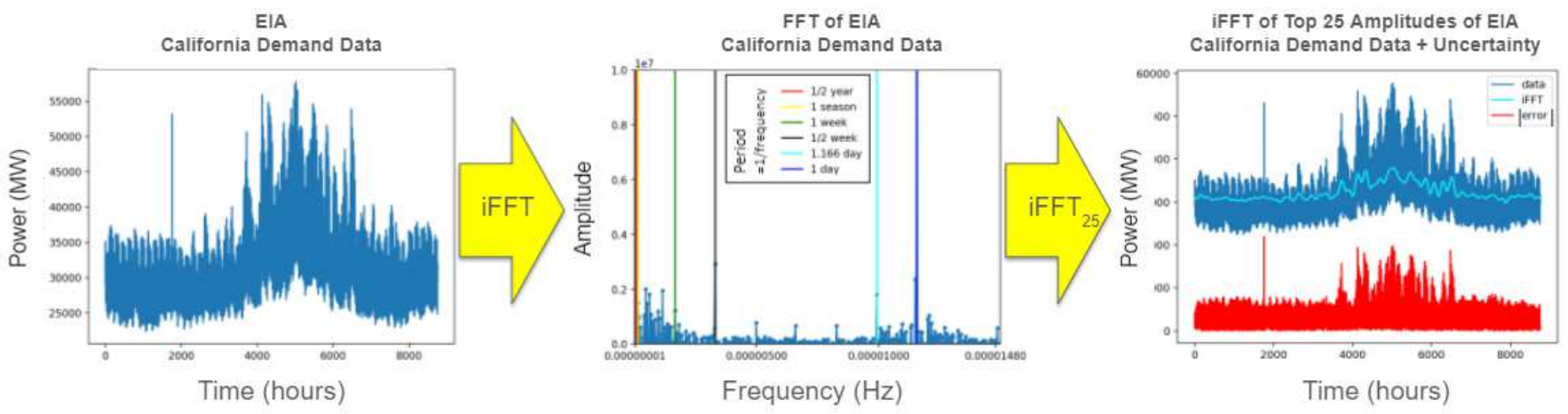

FIG. 4. One EIA Region's measured power load to the left. On the right is plotted the FFT of this power load results in key frequencies in this power load. When converting the frequencies into the units of period, the top six amplitudes are verified and understood based on climate and human behavior (for example, $\frac{1}{2}$ year $=$ winter/summer differences in power load discussed above). One city FFT power load to the left. On the right is plotted the inverse FFT using only the top 25 frequencies. Replotting the $i F F T_{25}$ in light blue illustrates the ability to predict the power load throughout the year and highlight the extreme uncertainty during various parts of the year. There is more error during the summer due to heat and air condition use (defined as absolute value of power load minus predicted power load).

with capacity shortage sensitivity analysis. Scenario $2 \mathrm{~B}$ uses the sizes for wind turbine(s) and solar panel(s) from Scenario $1 \mathrm{~A}$, but then uses actual measured power load, wind speed, and solar radiance and sizes ESDs, converters and WWTP biogas generator(s) to meet the uncertainty between predicted and actual measured data. The differences between predicted and actual measured data is how uncertainty is defined using a FFT, $i F F T_{25}$ and difference between the two novel methodologies.

Just as there is greater electricity demand during the evening than at dawn, there is greater electricity demand during summer than during winter, in a Mediterranean climate such as California EIA Region. This is simply due to the fact that Californians use more electricity cooling their homes in the summer than they do heating them in the winter. The periodic nature of electricity demand is complex and affects daily, weekly and annual usage patterns. [49]

Some of these fluctuations can be easily induced, but the majority of them are best measured deductively with Fourier analysis. Due to its computational efficiency, this analysis uses an FFT to determine the fundamental periodicity's in power load profiles (as well as solar radiance and wind speed). When given time-series data, an FFT outputs the data in the frequency domain. What this transformed data represents are the fundamental harmonics in the data and their respective prominence, labeled as amplitude in middle image in Figure 5.

Selecting an adequate number of prominent frequencies (here the top 25 amplitudes) and transforming them back into a time basis yields a predictive yearly power load (as well as solar radiance and wind speed). These results and two step process can be seen in Figure 5 as three images for the unaltered yearly power load actual data, the top 25 harmonics predicted data, as well as the difference between the two (yearly uncertainty and/or error profile).

A similar FFT and iFFT methodology was applied to

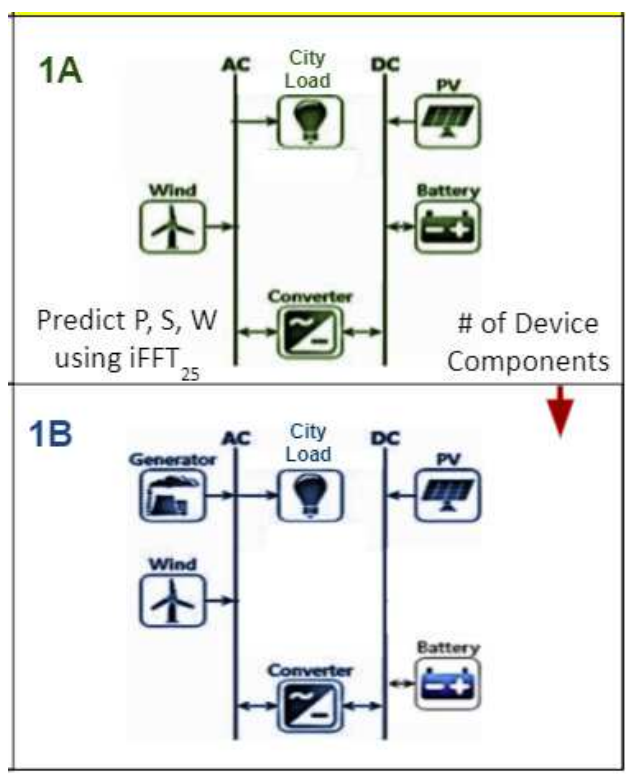

FIG. 5. Homer Pro mini grid model for Scenario 1 where the City Power Load in System A is an inverse FFT using the first 25 highest FFT amplitude frequencies as the prediction for the power load. System B then optimizes a WWTP biogas power generation system for meeting the real power load resulting in 100\% reliability. There are 200 Homer Pro models using Homer Energy's API algorithm which is one for each of the 100 US cities modeled for Scenarios $1 \mathrm{~A}$ and then again for Scenario 1B.

renewable energy power generation. Solar radiance and wind speed yielded interesting uncertainty yearly and diurnal behaviors which are discussed in the Discussion section and one city example is shown in Figures 10, 11, and 12. It is clear that optimally designing energy systems under uncertainty for $100 \%$ reliability is vital.

Therefore, Scenario 1 uses the designs from 1A (with 
inputs for solar, wind and powerload from $i F F T_{25}$ analysis) and 1B (with uncertainty). The fully designed system is verified to have a capacity shortage of $0 \%$ and then calculates the LCOE for Scenario 1. Scenario 1 is the HIC optimal energy system calculated by Homer Pro which includes predictability and uncertainty modeling for city power load, solar radiance, and wind speed. The full Scenario 1 includes a backup WWTP biogas generator sized to meet the uncertainty and optimal sizes the wind turbines, solar panels, batteries, and converters for each city.

\section{Scenario 2: LMIC-based Model}

Scenario 2A model consists of a minigrid with EIA measured region power load scaled by population for specific city power load, wind turbine (with wind speed @50m and elevation), converter, solar panels (with solar radiance), and batteries, but with capacity shortage sensitivity analysis. Scenario 2B uses the capacity shortage from 2A and sizes a WWTP biogas generator for $100 \%$ reliability.

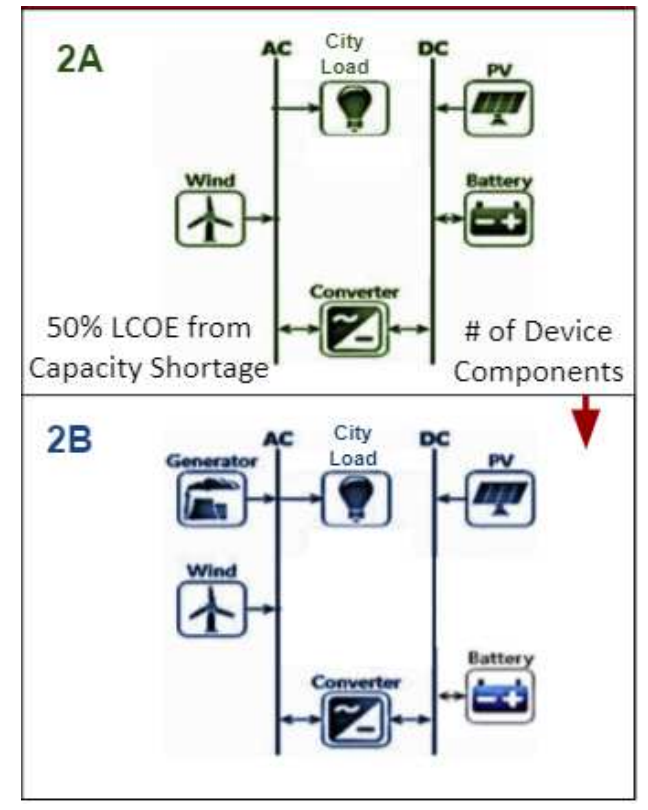

FIG. 6. Homer Pro mini grid model for Scenario 2 where System 2A accepts a $20 \%$ capacity shortage. System $2 \mathrm{~B}$ then uses a backup WWTP biogas generator for meeting the capacity shortage. System 2 is then recalculated to quantify COE with all subsystems involved and confirm results that the total power load is met with $0 \%$ capacity shortage.

Specifically, Scenario 2A allows for a $20 \%$ capacity shortage which typically results in an optimal mini grid design with at least a 50\% LCOE reduction compared with Scenario 0A's LCOE. Although some cities reduced LCOE by $50 \%$ when the city accepted a much lower capacity shortage [18]. Another Homer Pro model calculates the backup WWTP biogas generator to meet this capacity shortage and therefore have an overall $0 \%$ capacity shortage in the final energy system design.

In some cities a $1 \%$ capacity shortage immediately yielded an energy system design result with a LCOE saving of $50 \%$ compared to Scenario 0A's LCOE. The maximum limit of capacity shortage for this paper was $20 \%$. If an energy design reaches $20 \%$ capacity shortage and does not have a LCOE that is half of Scenario 0A's LCOE, then the capacity shortage is set at $20 \%$. In either case, Scenario 2B uses the capacity shortage from $2 \mathrm{~A}$ and sizes a biogas generator to meet this shortage of power. The full Scenario 2 includes a backup WWTP biogas generator sized for this capacity shortage and optimal sizes the wind turbines, solar panels, batteries, and converters for each city.

The authors then compare and contrast Scenarios 0A, $0 \mathrm{~B}, 1$, and 2. Many of the differences between the modeled cities are either (1) due to uncertainties in power load, solar radiance, and wind speed which are discussed first in the results section and/or (2) due to the differences in optimization objective function. For example, HIC energy systems tend to maximize profits for utility companies by using predictability algorithms (pricing mechanisms are many times due to this predictability). However, LMIC energy systems tend to minimize overdesign for mini grids by accepting a capacity shortage for the initial energy system design and then design a backup system for this capacity shortage. It is interesting that Scenario 2 (LMIC approach) finds optimal energy systems not initially considered and/or found in Scenarios $0 \mathrm{~A}, 0 \mathrm{~B}$, and 1 .

\section{RESULTS}

In validating these four scenario-based models, the authors first combined the 100 US cities results from the four main scenario results (Scenario 0A, Scenario 0B, Scenario 1, and Scenario 2). Figure 7 shows two LCOE peaks for optimal energy design and control results. The first LCOE result is that many cities have an optimal design and control result around $\$ 30 / \mathrm{MWh}$ (or $\$ 0.03 / \mathrm{kWh}$ ) and represents the percentage of cities with wind turbines and WWTP's biogas generation power typically calculated as the optimal energy system components (with batteries and charge controllers included). This is a realistic result according to (citation). The second LCOE result is that many cities have an optimal design and control result around $\$ 150 / \mathrm{MWh}$ (or $\$ 0.15 / \mathrm{kWh}$ ) and represents the percentage of cities with solar panels on rooftops typically calculated as the optimal energy system components (with batteries and charge controllers included) in-line with industry LCOE documented costs $[50,51]$.

The next results shown in Figure 8 suggest that WWTP plants should be promoted and encouraged to upgrade with biogas generators and/or turbines. No matter the scenario, System B is statistically the lowest COE 

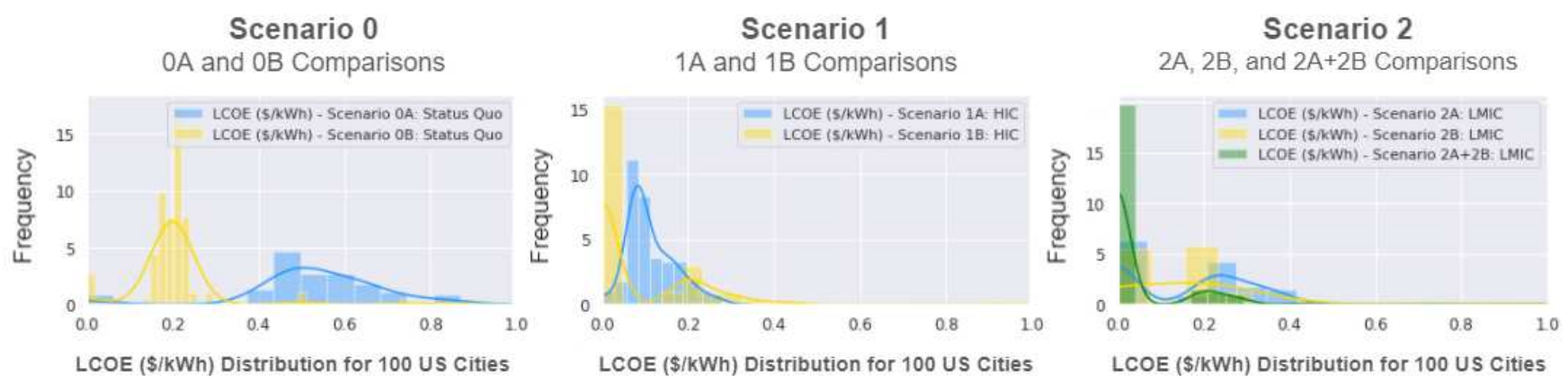

FIG. 7. Percentage of cities where the lowest LCOE $(\$ / \mathrm{kWh})$ was calculated from six specific optimization objective function pathways. This figure shows three images of LCOE distribution for 100 US cities' LCOE that resulted for scenario 0,1 , and 2 where blue is Scenario A, yellow is Scenario B. In Scenario 2, blue is status-quo systems sized with a capacity shortage, yellow is biogas generation power from WWTPs for only the capacity shortage, and green is the results with sized status-quo systems and back-up biogas generators combined.

\section{Final Scenario Comparisons}

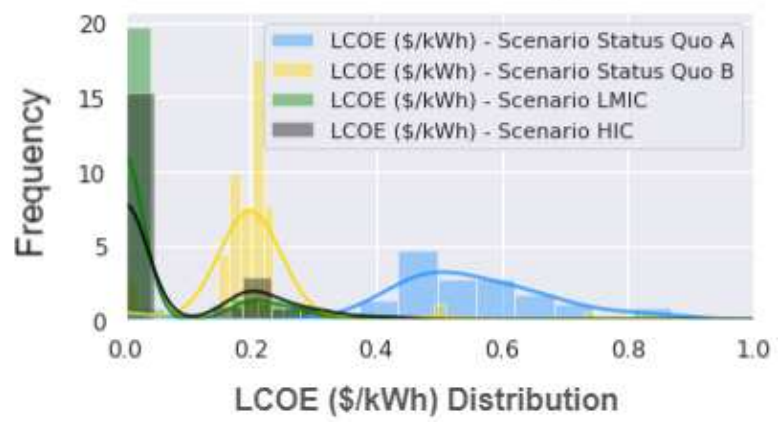

FIG. 8. Percentage of cities where the lowest LCOE $(\$ / \mathrm{kWh})$ was calculated from six specific optimization objective function pathways. This figure shows the LCOE distribution of all the cities and scenarios within the range between $\$ 0$ to $\$ 1.2 / \mathrm{kWh}$ (equivalent to $\$ 0$ to $\$ 1,200 / \mathrm{MWh}$ in the more common LCOE unit).

for the majority of cities.

The third result suggests that optimization objective functions yield different solutions. In Figure 9, the difference between status-quo systems from Scenario 0A and Scenario 0B clearly show that including biogas generation power at WWTPs reduces costs greatly for the majority of cities as shown in yellow LCOE distribution results. This is due to reduction of over-design in solar and wind turbine systems to meet uncertainties in power demand, solar radiance, and wind speed within and around the cities as shown in blue LCOE distribution results. However, the Scenario 1 sized the status-quo energy system components with the $i F F T_{25}$ power demand, solar radiance, and wind speed and then used biogas generation power at WWTPs to meet the uncertainty in human behavior (power demand) and renewable energy (solar radiance and wind speed). There is still a peak with cities' renewable energy system LCOE around $\$ 150 / \mathrm{MWh}$ (or $\$ 0.15 / \mathrm{kWh}$ ), but the greatest peak is below $\$ 40 / \mathrm{MWh}$ (or $\$ 0.04 / \mathrm{kWh}$ ). This technology-based solution to use power load prediction is common in HICs and results are shown in grey shade and black line for these Scenario 1 LCOE distribution results. However, the interesting finding is that Scenario 2 sized the status-quo energy system components first by accepting a capacity shortage and then used biogas generation power at WWTPs to meet the capacity shortage so that the combined energy system components are $100 \%$ reliable (i.e. no capacity shortage at all). It is common in LMICs that energy systems are designed to meet 80 to $90 \%$ of the the power load demand by accepting a 10 to $20 \%$ capacity shortage because costs are typically $50 \%$ less. When taking this innovative design approach, but using biogas generation power at WWTPs to meet the initially accepted capacity shortage, there are even many US cities who would have lower LCOEs using a LMIC-based optimization approach instead of a technology-based approach. Societal norms and values matter and even though the majority of global energy system designers use either a Scenario 0A, Scenario 0B, or Scenario 1A (HIC) optimization approach, a new methodology should be considered and valued as well. This new methodology is due to the innovation found within energy system designs within LMICs (typically who have dual DC and AC minigrid modes as well). In LMICs, energy system designers design an initial renewable energy system assuming a 10-20\% capacity shortage is inevitable to avoid overdesign (and because practically they can save 50\% in LCOE). However, this is a benefit and not a deficit and consequently yields new energy system options.

\section{DISCUSSION}

Moving forward with this research, it is vital to sustain $100 \%$ reliability where reliability is already $100 \%$. However, renewable energy systems have unique nonGaussian uncertainty distributions depending on power load, wind speed, and solar radiance. When using bio- 


\section{Overall Result: All Scenarios \\ Two LCOE Peaks: \$30/MWh and \$150/MWh}

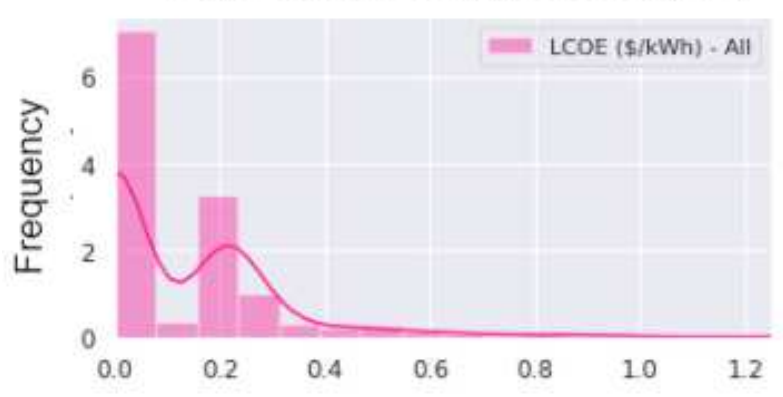

LCOE (\$/kWh) Distribution for 100 US Cities

FIG. 9. This figure shows the total LCOE for the 100 cities for each total scenario: Status-quo of Wind, Solar and Batteries (0A), Status-quo with Biogas Generators at Waste Water Treatment Plants -WWTPs (0B), HIC country optimization pathway using technology to model expected powerload $\left(i F F T_{25}\right)$ with WWTP power generation meeting the actual powerload which can be greater than expected powerload (1B), and LMIC country optimization pathway using costs constraints to meet the majority of power load with an accepted power load shortage, but meeting this power load shortage with back-up from WWTPs power generation.

gas generation power at WWTPs to meet these uncertainties, the authors suggest using the complexity of renewable energy and human behavior as a benefit instead of a deficit. The biogas generation power at WWTPs meets the uncertainty and/or capacity shortage only and is not sized unrealistically large because the design criteria is not for all the power load demand. Furthermore, future research should begin to embrace energy policy scientifically-driven optimal design and control strategies based on uncertainty in power load demand, solar radiance, and wind speed as shown in Figures 10, 11, and 12, respectively.

This paper resulted in data results for 100 cities in terms of base power load, solar radiance, and wind speed predictions $\left(i F F T_{25}\right)$ as well as the positive uncertainties (actual is above the $i F F T_{25}$ prediction) and negative uncertainties (actual is below the $i F F T_{25}$ prediction). For example, with solar radiance, the positive uncertainties typically occur during the middle of the day whereas the negative uncertainties typically occur in the early morning or evening.

Whereas for the wind speed, the positive uncertainties occur during the late afternoon or early evening and the negative uncertainties late at night or extremely early in the morning. Power load positive uncertainties happen in the middle of the day during the summer due to air conditioning human behavior and negative uncertainties occur typically during the early evening. As human societies try to move to more renewable energy systems to avoid a sixth extinction, $100 \%$ reliability from renew- able energy systems will avoid energy crises and this can happen if uncertainties in renewable energy and human behavior is seen as a benefit for creative solutions.

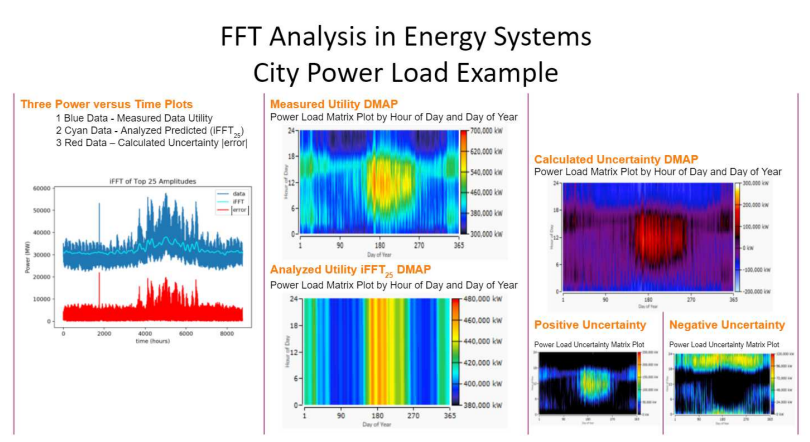

FIG. 10. An EIA-based City Power Load for a year (typically either 2018, 2017, 2016, or combined) in terms of measured power demand, predictability and uncertainty results (with discussion about negative and positive uncertainties occurring at various times of the year).

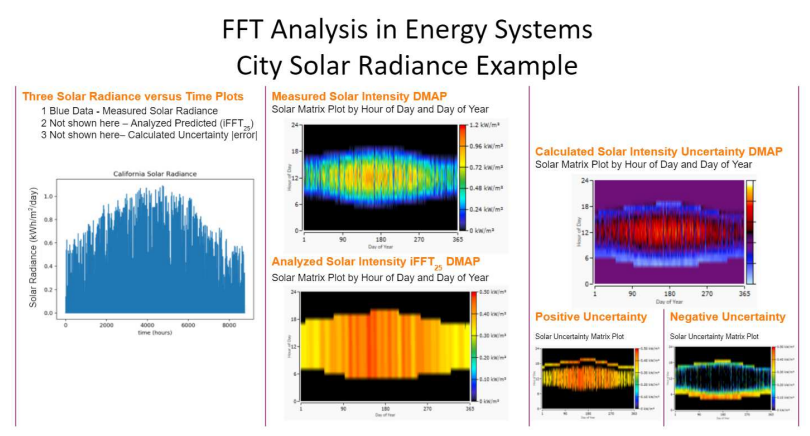

FIG. 11. Homer Pro downloaded NASA data for a year in terms of measured solar radiance, predictability and uncertainty results (with discussion about negative and positive uncertainties occurring at various times of the year).

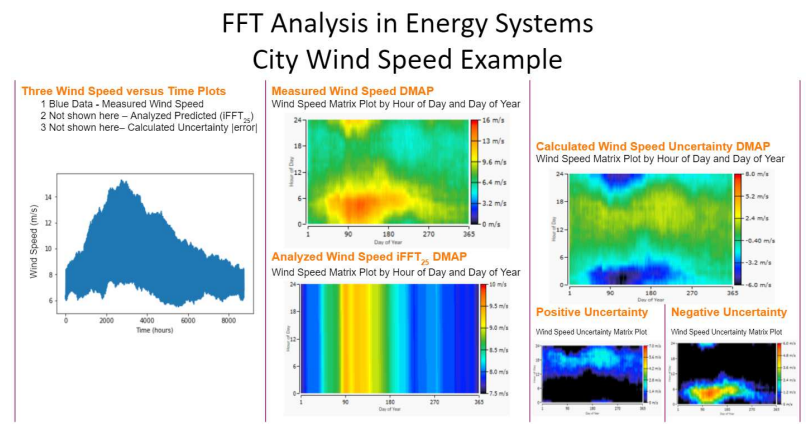

FIG. 12. Homer Pro downloaded NASA data for a year in terms of measured wind speed at $50 \mathrm{~m}$, predictability and uncertainty results (with discussion about negative and positive uncertainties occurring at various times of the year). 


\section{CONCLUSIONS}

The answer to the question "how can we better incorporate renewable energies into the grid?" is as counterintuitive as it is innovative: Use the complexity of renewable energy as a benefit rather than a deficit, and design with renewable energy complexity. By applying hardearned LMIC and/or rural or islanded minigrid design and control optimal $[7,18,20-22,25,29,31,49,52-$ 54 ] choices including accepting capacity shortage to save money on energy system and use this money to save lives (for example energy systems designed in health care facilities [55]), US cities can both increase affordability and increase reliability by incorporating WWTP electricity generation into the portfolio for an increase in the likelihood to mitigate and adapt to climate change. Although technology-driven approaches to find ways to incorporate renewable energies into the grid is profitable for businesses with new patents in HICs, it is not the only option. Regardless of methodology (LMIC and/or HIC) and/or assumptions about how to design and control a renewable energy system, choosing biogas power generation at WWTPs is definitely a viable option (citations) for many cities.

\section{DATA AVAILABILITY}

The solar radiance profile data used in this analysis was obtained from the NASA and NOAA based on city locations and longitude and latitude [56, 57]. The data consists of a cross-sample of cities in the US based on hour-by-hour average solar radiance (8,760 data points per city). Since there are 100 US cities, there are 876,000 data points in this measured solar radiance data set and 876,000 data points in the $i F F T_{25}$ predicted solar radiance data set.

The wind speed profile data used in this analysis was obtained from the NASA based on city locations and longitude and latitude [56-58]. The data consists of a cross-sample of cities in the US based on hour-by-hour average wind speed (8,760 data points per city). Since there are 100 US cities, there are 876,000 data points in this measured wind speed data set and 876,000 data points in the $i F F T_{25}$ predicted wind speed data set.

The power load profile data used in this analysis was obtained from the EIA data from NERC regions $(8,760$ data points for each EIA region and 100 US cities or 876,000 data points). The population of the NERC region and population of the city was used to scale the EIA NERC region's measured power load for a specific city power load $[59,60]$. The data consists of a crosssample of cities in the US based on hour-by-hour average power load (assumed scalable). There are 876,000 data points in this measured power load data set and 876,000 data points in the $i F F T_{25}$ predicted powerload data set.

Then each city is modeled in Homer Pro Desktop and Homer Pro API script for Status-Quo Scenario 0A (wind turbines, solar panels, batteries and converters), Scenario 0B (adding WWTP biogas generators), HIC Scenario 1 (using predictability and uncertainty), and LMIC Scenario 2 (using capacity shortage in $2 \mathrm{~A}$ to design backup energy system in $2 \mathrm{~B}$ ). There are therefore also an additional 2,628,000 capacity shortage powerload data points from $2 \mathrm{~A}$ that are inputted into $2 \mathrm{~B}$. The number of WWTP facilities that are available in each city (100 data points) [41]. A city's rooftop coverage (100 data points). The elevation for each city (100 data points). The population for each city (100 data points). The population for each EIA NERC region (22 data points). Total NERC region and city's area (200 data points). Not including the data from the time series results from Homer Pro outputs, the amount of data the authors collected and analyzed is around 3 million data points. All of this data and Homer Pro API script will be downloadable from links within the supplemental materials where methodology, data and script is explained in detail with a discussion about using NREL's API script for readers and other minigrid optimization algorithm's the authors have used (data available to journal for verification upon acceptance of publication).
[1] A. Perera, K. Javanroodi, and V. M. Nik, Climate resilient interconnected infrastructure: Co-optimization of energy systems and urban morphology, 285, 116430.

[2] M. Mohammadi, S. Hosseinian, and G. Gharehpetian, Optimization of hybrid solar energy sources/wind turbine systems integrated to utility grids as microgrid (MG) under pool/bilateral/hybrid electricity market using PSO, Solar Energy 86, 112 (2012).

[3] W. Al-Saedi, S. W. Lachowicz, D. Habibi, and O. Bass, Voltage and frequency regulation based DG unit in an autonomous microgrid operation using Particle Swarm Optimization, International Journal of Electrical Power \& Energy Systems 53, 742 (2013).

[4] W. Al-Saedi, S. W. Lachowicz, D. Habibi, and O. Bass,
Power flow control in grid-connected microgrid operation using Particle Swarm Optimization under variable load conditions, International Journal of Electrical Power \& Energy Systems 49, 76 (2013).

[5] M. Chennaif, M. Maaouane, H. Zahboune, M. Elhafyani, and S. Zouggar, Tri-objective techno-economic sizing optimization of off-grid and on-grid renewable energy systems using electric system cascade extended analysis and system advisor model, 305, 117844.

[6] S.-R. Lim, D. Park, and J. M. Park, Analysis of effects of an objective function on environmental and economic performance of a water network system using life cycle assessment and life cycle costing methods, Chemical Engineering Journal 144, 368 (2008). 
[7] S. K. Nandi and H. R. Ghosh, enProspect of wind-PVbattery hybrid power system as an alternative to grid extension in Bangladesh, Energy 35, 3040 (2010).

[8] Z. Huang, T. Zhu, D. Irwin, A. Mishra, D. Menasche, and P. Shenoy, enMinimizing Transmission Loss in Smart Microgrids by Sharing Renewable Energy, ACM Transactions on Cyber-Physical Systems 1, 1 (2016).

[9] V. Azarova, D. Engel, C. Ferner, A. Kollmann, and J. Reichl, enExploring the impact of network tariffs on household electricity expenditures using load profiles and socio-economic characteristics, Nature Energy 3, 317 (2018).

[10] A. Acakpovi, E. Ben Hagan, and M. Bennet Michael, engCost Benefit Analysis of Self-Optimized Hybrid SolarWind-Hydro Electrical Energy Supply as compared with HOMER Optimization, International Journal of Computer Applications 114, 32 (2015), oCLC: 551898616.

[11] X. Lu, M. B. McElroy, W. Peng, S. Liu, C. P. Nielsen, and H. Wang, Challenges faced by China compared with the US in developing wind power, Nature Energy 1, 16061 (2016).

[12] T. Levin and V. M. Thomas, enA mixed-integer optimization model for electricity infrastructure development, Energy Systems 4, 79 (2013).

[13] R. K. Jain, J. Qin, and R. Rajagopal, Data-driven planning of distributed energy resources amidst sociotechnical complexities, 2, 17112.

[14] B. A. Nieto-Díaz, A. F. Crossland, and C. Groves, A levelized cost of energy approach to select and optimise emerging PV technologies: The relative impact of degradation, cost and initial efficiency, 299, 117302.

[15] M. Sheha, K. Mohammadi, and K. Powell, Technoeconomic analysis of the impact of dynamic electricity prices on solar penetration in a smart grid environment with distributed energy storage, 282, 116168.

[16] E. Kolbert, The sixth extinction: an unnatural history (Bloomsbury).

[17] R. Akikur, R. Saidur, H. Ping, and K. Ullah, Comparative study of stand-alone and hybrid solar energy systems suitable for off-grid rural electrification: A review, Renewable and Sustainable Energy Reviews 27, 738 (2013).

[18] M. Ismail, M. Moghavvemi, and T. Mahlia, Design of an optimized photovoltaic and microturbine hybrid power system for a remote small community: Case study of Palestine, Energy Conversion and Management 75, 271 (2013).

[19] A. Perera, R. Attalage, K. Perera, and V. Dassanayake, Designing standalone hybrid energy systems minimizing initial investment, life cycle cost and pollutant emission, Energy 54, 220 (2013).

[20] J. Kaldellis, D. Zafirakis, E. Kaldelli, and K. Kavadias, Cost benefit analysis of a photovoltaic-energy storage electrification solution for remote islands, Renewable Energy 34, 1299 (2009).

[21] D. Akinyele, O. Babatunde, C. Monyei, L. Olatomiwa, A. Okediji, D. Ighravwe, O. Abiodun, M. Onasanya, and K. Temikotan, enPossibility of solar thermal power generation technologies in Nigeria: Challenges and policy directions, Renewable Energy Focus 29, 24 (2019).

[22] A. Al-Karaghouli and L. Kazmerski, enOptimization and life-cycle cost of health clinic PV system for a rural area in southern Iraq using HOMER software, Solar Energy 84, 710 (2010).

[23] S. Sterl, D. Fadly, S. Liersch, H. Koch, and W. Thiery,
Linking solar and wind power in eastern africa with operation of the grand ethiopian renaissance dam, 6, 407.

[24] J. Cohen, K. Moeltner, J. Reichl, and M. Schmidthaler, enEffect of global warming on willingness to pay for uninterrupted electricity supply in European nations, Nature Energy 3, 37 (2018).

[25] S. Szabó, M. Moner-Girona, I. Kougias, R. Bailis, and K. Bódis, enIdentification of advantageous electricity generation options in sub-Saharan Africa integrating existing resources, Nature Energy 1, 10.1038/nenergy.2016.140 (2016).

[26] A. Mechtenberg, B. McLaughlin, M. DiGaetano, A. Awodele, L. Omeeboh, E. Etwalu, L. Nanjula, M. Musaazi, and M. Shrime, Health care during electricity failure: The hidden costs, 15, e0235760.

[27] A. Duffy, M. Hand, R. Wiser, E. Lantz, A. Dalla Riva, V. Berkhout, M. Stenkvist, D. Weir, and R. LacalArántegui, Land-based wind energy cost trends in germany, denmark, ireland, norway, sweden and the united states, 277, 114777.

[28] M. Allen, H. de Coninck, O. P. Dube, O. HoeghGuldberg, D. Jacob, K. Jiang, A. Revi, J. Rogelj, J. Roy, D. Shindell, W. Solecki, M. Taylor, P. Tschakert, and H. Waisman, IPCC 1.5 Special Report.pdf (2018).

[29] M. Moghavvemi, M. Ismail, B. Murali, S. Yang, A. Attaran, and S. Moghavvemi, Development and optimization of a PV/diesel hybrid supply system for remote controlled commercial large scale FM transmitters, Energy Conversion and Management 75, 542 (2013).

[30] P. Denholm, M. O'Connell, G. Brinkman, and J. Jorgenson, en Overgeneration from Solar Energy in California. A Field Guide to the Duck Chart, Tech. Rep. NREL/TP6A20-65023, 1226167 (2015).

[31] P. Basak, S. Chowdhury, S. Halder nee Dey, and S. Chowdhury, A literature review on integration of distributed energy resources in the perspective of control, protection and stability of microgrid, Renewable and Sustainable Energy Reviews 16, 5545 (2012).

[32] N. Kittner, F. Lill, and D. M. Kammen, Energy storage deployment and innovation for the clean energy transition, Nature Energy 2, 17125 (2017).

[33] O. Schmidt, A. Hawkes, A. Gambhir, and I. Staffell, The future cost of electrical energy storage based on experience rates, 2, 17110 .

[34] M. M. Rahman, A. O. Oni, E. Gemechu, and A. Kumar, The development of techno-economic models for the assessment of utility-scale electro-chemical battery storage systems, 283, 116343.

[35] T. W. Hudiburg, W. Wang, M. Khanna, S. P. Long, P. Dwivedi, W. J. Parton, M. Hartman, and E. H. DeLucia, Impacts of a 32-billion-gallon bioenergy landscape on land and fossil fuel use in the US, Nature Energy 1, 15005 (2016).

[36] L. C. Stokes and C. Warshaw, Renewable energy policy design and framing influence public support in the United States, Nature Energy 2, 17107 (2017).

[37] B. Mendecka, D. Chiappini, L. Tribioli, and R. Cozzolino, A biogas-solar based hybrid off-grid power plant with multiple storages for united states commercial buildings, 179, 705 .

[38] J. H. R. Mensah, A. T. Y. L. Silva, I. F. S. d. Santos, N. d. S. Ribeiro, M. J. Gbedjinou, V. G. Nago, G. L. Tiago Filho, and R. M. Barros, Assessment of electricity generation from biogas in benin from energy and eco- 
nomic viability perspectives, $\mathbf{1 6 3}, 613$.

[39] B. Liu and D. Rajagopal, Life-cycle energy and climate benefits of energy recovery from wastes and biomass residues in the united states, $\mathbf{4}, 700$.

[40] Energy Information Administration, enU.S. Battery Storage Market Trends, , 32 (2018).

[41] Environmental Protection Agency, enOpportunities for Combined Heat and Power at Wastewater Treatment Facilities: Market Analysis and Lessons from the Field, Proceedings of the Water Environment Federation 2012, 4532 (2012).

[42] Jess Jiang, enThe Price Of Electricity In Your State (2011).

[43] Vermont Agency of Agriculture, Food, \& Markets, Digester on a Dairy Farm.

[44] Nora Goldstein, en-USFarm Digester Evolution In Vermont (2013).

[45] A. D. Cuéllar and M. E. Webber, enCow power: the energy and emissions benefits of converting manure to biogas, Environmental Research Letters 3, 034002 (2008).

[46] GreenBiz Editors, enVermont Farms Turn on to Cow Power (2006).

[47] R. Bedoić, H. Dorotić, D. R. Schneider, L. Čuček, B. Ćosić, T. Pukšec, and N. Duić, Synergy between feedstock gate fee and power-to-gas: An energy and economic analysis of renewable methane production in a biogas plant, 173, 12.

[48] A. E. Motter, S. A. Myers, M. Anghel, and T. Nishikawa, enSpontaneous synchrony in power-grid networks, Nature Physics 9, 191 (2013).

[49] J. Kaldellis, D. Zafirakis, and K. Kavadias, Minimum cost solution of wind-photovoltaic based stand-alone power systems for remote consumers, Energy Policy 42, 105
(2012).

[50] D. Ray, Lazard's levelized cost of energy analysis-version 14.0, , 21.

[51] M. Wilson, Lazard's levelized cost of storage analysis-version 6.0, , 40.

[52] J. Kaldellis and D. Zafirakis, Optimum sizing of standalone wind-photovoltaic hybrid systems for representative wind and solar potential cases of the Greek territory, Journal of Wind Engineering and Industrial Aerodynamics 107-108, 169 (2012).

[53] B. Robertson, J. Bekker, and B. Buckham, Renewable integration for remote communities: Comparative allowable cost analyses for hydro, solar and wave energy, 264, 114677.

[54] R. E. Silverman, R. J. Flores, and J. Brouwer, Energy and economic assessment of distributed renewable gas and electricity generation in a small disadvantaged urban community, 280, 115974.

[55] A. R. Mechtenberg, M. Musaazi, N. Senabulya, and J. V. Makanda, Socio-technical implication of renewable energy sources: African health care case study with MonteCarlo simulations, in 2012 IEEE International Symposium on Sustainable Systems and Technology (ISSST) (2012) pp. $1-6$.

[56] NOAA, Search | Climate Data Online (CDO) | National Climatic Data Center (NCDC) ().

[57] NASA, Graphic: The relentless rise of carbon dioxide.

[58] NOAA, Measurements ().

[59] Energy Information Administration, EnglishAnnual Energy Review, Tech. Rep. (Energy Information Administration, 2018).

[60] Energy Information Administration, Open Data. 